\title{
CERN seeks bank loans to construct LHC
}

Munich. Member states of CERN, the European Laboratory for Particle Physics in Geneva, will almost certainly be asked next month to approve the raising of bank loans to allow the Large Hadron Collider to be built as planned by 2005 .

The SFr2.6-billion (US\$2.06-billion) collider will be the world's most powerful particle accelerator. The project was thrown into confusion in July when Germany decided, for budgetary reasons, significantly to reduce its promised contribution for the next four years (see Nature 382, 285; 1996).

CERN's committee of council agreed in September that other member states should not be asked to make up Germany's shortfall. Instead, it proposed that these countries should reduce their own contributions proportionately, and should ask CERN to make up the resulting 9 per cent annual shortfall partly by internal savings and partly by raising loans to extend the payment period by a further three years after the end of construction (see Nature 383, 370; 1996).

After several weeks of reflection, the committee agreed last week to stick to this recommendation. Germany has not moved from its position, and other financial options put forward, such as phasing in the German cuts more slowly, or trying to build the collider on a smaller budget, were rejected as unrealistic.

The committee stresses that it does not want to consider a further option, that of building the collider in two phases over a longer period. That would make it unattractive to potential partners such as the United States, whose hoped-for participation in the project could help bring forward the completion date.

The new financing plan, with its reduced annual contributions from all 19 member states, is likely to prove acceptable to CERN's decision-making council meeting next month. In the United Kingdom it would release three-quarters of the additional $£ 65$ million ( $\$ 39.6$ million) that scientists have been demanding for domestic particle physics research in the next decade.

Alison Abbott

\section{Japan's tokamak success boosts its bid for reactor}

Tokyo. Japan's upgraded tokamak fusion reactor, JT-60U, has achieved a long soughtafter goal of reproducing conditions 'equivalent' to breakeven, where energy output equals energy input. This will strengthen Japan's bid to host the International Thermonuclear Experimental Reactor (ITER), if the machine, planned to be built by Europe, the United States, Russia and Japan, is ever realized.

The JT-60U, an upgraded version of the JT-60 tokamak that originally started operations in 1985, achieved its goal in experimental runs on 31 October and 1 November. The tokamak uses a deuterium-deuterium fuel, which has much lower reactivity than the deuterium-tritium fuel that is expected to be used in the first reactors for practical energy production, such as ITER. As a result, the experiments did not actually achieve breakeven.

Rather, researchers at the Japan Atomic Energy Research Institute (JAERI), which operates JT-60U, deduced that in the conditions attained in the experiments - an ion temperature of $1.9 \times 10^{8} \mathrm{~K}$ and an electron density of $9.7 \times 10^{19} \mathrm{~m}^{-3}$ in the plasma during a confinement time of 0.97 seconds - the ratio of energy output to input would have been 1.05 in the case of a deuterium-tritium fuel. As such, the Japanese results represent the same level of achievement as those obtained more than four years ago at the Joint European Torus in the United Kingdom.

But the Japanese media are interpreting the results as a sign that Japan has made a significant step towards the realization of ITER. A press release from JAERI, for example, emphasizes that the experiments used a reversed shear mode of operation that Japan and some other ITER participants are proposing for ITER.

Fusion scientists point out that the confinement improvement achieved with the reversed shear approach is only transient, and it will not be practical until - and if - it can be sustained. "I would welcome efforts by the JT-60U team in the coming years to verify this point," says Atsuo Iiyoshi, head of Japan's National Institute for Fusion Science, which, in a different approach, is building the world's largest helical fusion device.

Japanese government officials and industrialists do not hide the fact that they are keen to host ITER. Three locations are competing to be put forward as Japan's proposed site: the Mutsu Ogawara district in Aomori Prefecture on the northern tip of Japan's main island, close to where a huge nuclear fuel recycling and processing facility is being built; Tomakomai in the northern island of Hokkaido; and Naka in Ibaraki Prefecture, northeast of Tokyo, the site of part of JAERI and Japan's laboratory for the engineering design phase of ITER.

Keidanren, a powerful federation of Japanese companies, is "strongly" backing the idea of Japan hosting ITER, according to a spokesman. Japanese industry apparently sees opportunities for lucrative contracts for the construction of ITER which will cost billions of dollars - and the opportunity to learn about this technology.

Japan is even said to have put forward an informal proposal to pay up to 70 per cent of the total costs of ITER, estimated at more than US $\$ 10$ billion, if it can host the demonstration reactor (see Nature 380, 655; 1996). An official of the Science and Technology Agency, which oversees Japan's ITER programme, says the report of a 70 per cent offer is "not correct". But a Keidanren spokesman says that even if Japan has to pay this proportion, it would be a "good idea" for the country to host ITER.

\section{IMAGE UNAVAILABLE FOR COPYRIGHT REASONS}

The future of ITER itself hangs in the balance, as the United States cuts back on fusion research, and Europe questions whether magnetic confinement is the best approach to fusion (see Nature 380, 655; 1996). Japan's support could thus be critical.

There is disagreement, however, in Japan's fusion science community as to whether Japan should propose to host ITER at this stage. Iiyoshi says that he personally feels that the founding principle of equal sharing among ITER partners seems to be "unravelling" and that the project needs to be "fundamentally restructured" before future research work and the location can be discussed.

"The current ITER design represents a compromise among sometimes conflicting demands from the participants," says Iiyoshi, emphasizing that success is being achieved at the expense of innovation. He complains that this design philosophy "has resulted in a costly behemoth that has shied away from innovative but riskier features", and concludes that the machine has become "too predictable" to "ignite intellectual enthusiasm". But such views are unlikely to deter powerful supporters of ITER in Japan. 